\title{
ANALISIS JEJAK EKOLOGIS MELALUI STUDI JEJAK KARBON PADA TRANSPORTASI DARAT
}

\author{
Farha Dapas ${ }^{1)}$ \\ ${ }^{1)}$ Program studi Biologi FMIPA, Universitas Sam Ratulangi Manado \\ e-mail : ayafarha@yahoo.com
}

\begin{abstract}
ABSTRAK
Analisis jejak ekologis adalah salah satu alat perencanaan dalam pembangunan berkelanjutan. Konsep ini tidak hanya untuk menilai aktivitas manusia dalam kaitannya dengan keberlanjutan tetapi juga efektif untuk meningkatkan kesadaran masyarakat dan para pembuat keputusan untuk mengelola sumber daya alam secara lebih baik dan komprehensif. Analisis Jejak ekologis adalah alat untuk mengukur konsumsi sumberdaya alam dan batasan asimilasi limbah yang dihasilkan oleh populasi manusia atau ekonomi dikaitkan dengan daya dukung lahan. Salah satu bagian dalam analisis jejak ekologis adalah studi jejak karbon, dengan menghitung emisi karbon dioksida melalui pembakaran bahan bakar fosil pada kendaraan bermotor. Hasilnya dapat memberi gambaran mengenai dampak aktivitas manusia terhadap lingkungan dalam satuan tertentu (lahan bioproduktif) dan dapat dihubungkan dengan daya dukung bumi (biokapasitas).
\end{abstract}

Kata kunci : jejak ekologis, jejak karbon, biokapasitas

\section{ECOLOGICAL FOOTPRINT ANALYSIS BY CARBON FOOTPRINT STUDY ON LAND TRANSPORTATION}

\begin{abstract}
Ecological Footprint analysis is one of the planning tool or indicator in sustainable development. This concept is not only to assess human activity in regard with sustainability but also effectively to raise community awareness and the decision maker to manage the resources better and comprehensive. Ecological Footprint analysis is an accounting tool that enables us to estimate the resource consumption and waste assimilation requirements of a defined human population or economy in terms of a corresponding productive land area. Carbon footprint can be studied by counting the Carbon dioxide emission or waste through fossil fuels consumption in vehicles. The result shows the human activities impact on environment in certain unit (bioproductive land) and can be connected with earth carrying capacity (biocapacity).
\end{abstract}

Keywords: ecological footprint, carbon footprint, biocapacity

\section{PENDAHULUAN}

Alam menyediakan kebutuhan hidup mendasar bagi umat manusia. Selain menyediakan material, alam mampu menyerap limbah hasil ekstraksi dalam jumlah tertentu. Namun, semakin meningkatnya aktivitas manusia semakin meningkat pula kebutuhannya. Bila kebutuhan primer dan sekunder seperti sandang, pangan dan papan, telah terpenuhi maka kebutuhan selanjutnya adalah kebutuhan tersier atau gaya hidup (lifestyle), seperti alat transportasi. Kebutuhan akan alat transportasi menjadi semakin penting, sehingga kebutuhan akan energi untuk mobilitas juga semakin tinggi. Dengan semakin terbukanya akses memiliki kendaraan (mobil/motor), ketergantungan akan bahan bakar fosil pun akan semakin meningkat. Akibat yang tidak dapat dihindari adalah emisi $\mathrm{CO}_{2}$ dari bahan bakar fosil yang merupakan sumber utama gas rumah kaca saat ini. Bila penggunaan energi berlangsung secara terus menerus akan menghasilkan gap antara kebutuhan manusia dan ketersediaannya di alam. Selanjutnya sisa buangan, seperti emisi karbon berkontribusi sangat nyata bagi pemanasan global.

Untuk dapat hidup secara berkelanjutan, manusia harus menggunakan produk esensial dan proses alamiah tidak 
lebih cepat daripada yang dapat diperbaharui, serta menghasilkan sampah tidak lebih cepat daripada yang dapat diserap oleh alam. Wackernagel (2011) dari Global Footprint Network menghitung kecepatan output dengan mengukur biokapasitas, yakni kemampuan alam untuk memperbarui sumber daya dan menyediakan layanan ekologi. Hal ini menjadi peringatan bahwa kemanapun masa depan akan pergi, apakah manusia menghindari bencana iklim atau justru meneruskannya, dengan cara-cara business as usual, peningkatan konsumsi, populasi penduduk dan emisi $\mathrm{CO}_{2}$, akan mempercepat tekanan terhadap biokapasitas.

Oleh karena itu penting bagi kita untuk mengetahui seberapa besar jejak ekologis yang kita tinggalkan melalui aktivitas yang dilakukan sehari-hari. Salah satu cara dengan menghitung jejak karbon (Carbon Footprint) yang dihasilkan dari penggunaan kendaraan pribadi untuk menggambarkan tingkat konsumsi maupun emisi $\mathrm{CO}_{2}$ yang dihasilkan dari aktivitas berkendara selama periode tertentu, sebagai bagian dari Analisis Ecological Footprint.

\section{ECOLOGICAL FOOTPRINT : MENGUKUR CARBON FOOTPRINT}

\section{A. Prinsip dan Konsep Ecological Footprint}

Sebuah konsep untuk melakukan perhitungan terhadap aliran energi dan siklus materi dari / ke ekonomi dan dikonversikan ke lahan atau perairan yang mendukung aliran ini telah dibangun oleh Rees dan Wackernagel (1996). Konsep ini tidak hanya menilai keberlanjutan aktivitas manusia saat ini, tapi juga efektif membangun kesadaran masyarakat serta membantu para pengambil kebijakan. Konsep yang disebut Ecological Footprint (EF) didasarkan pada pencarian indikator berkelanjutan, khususnya mengukur pemanfaatan sumberdaya alam oleh manusia dikaitkan dengan daya dukung. Hasilnya dapat memberi gambaran mengenai dampak aktivitas manusia terhadap lingkungan dalam satuan tertentu (lahan bioproduktif) dan dapat dihubungkan dengan daya dukung bumi (biokapasitas). Biokapasitas merupakan langkah awal untuk menentukan dampak aktivitas manusia terhadap lingkungan, sehingga faktor yang diukur adalah berapa besar sumberdaya dalam satuan lahan bioproduktif yang digunakan untuk menghasilkan atau memproduksi barang atau jasa yang dikonsumsi oleh sejumlah populasi tertentu dan untuk menyerap atau mengasimilasi limbah yang dihasilkan menggunakan teknologi yang umum (Chambers et al.,, 2000 dalam Septiarani, 2010). Satuan yang biasa digunakan adalah hektar dan dapat dihitung menurut individu, komunitas, perdesaan, perkotaan, provinsi, negara bahkan populasi global secara keseluruhan. Ecological Footprint juga dapat menghitung konsumsi suatu organisasi, aktivitas manusia tertentu atau barang dan jasa tertentu (Rees dan Wackernagel, 1996).

Perhitungan EF yang telah dilakukan berdasarkan data (CBD, 2010) kebutuhan manusia akan aset ekologi terus meningkat pada periode 1961-2007. Permintaan akan sumberdaya alam dan jasa ekologis mencapai hamper 50\% sejak tahun 1961 sehingga saat ini menjadi $151 \%$ dari kapasitas yang ada, atau setara 1.5 kali nilai planet. Permintaan sumberdaya dan jasa ekologis meningkat pada semua tipe lahan, meskipun permintaan dari hutan dan serapan karbon meningkat paling cepat. Perbedaan nilai footprint dapat ditemukan pada level regional sebagai nilai konsumsi per kapita, dimana yang tertinggi adalah Amerika Utara (7.9 gha/kapita) dan Eropa (4.7), serta yang terendah adalah di Afrika (1.4) dan Asia Pasifik (1.8).

\section{B. Pentingnya Pendekatan Ecological Footprint (EF) / Carbon Footprint (CF) untuk Sustainable Development \\ Carbon Footprint merupakan suatu} ukuran jumlah total dari hasil emisi karbon dioksida yang secara langsung maupun tidak langsung disebabkan oleh aktivitas atau akumulasi yang berlebih dari penggunaan produk dalam kehidupan sehari-hari, misalnya pembakaran bahan bakar fosil dari penggunaan kendaraan bermotor (Wiedemann dan Minx, 2007 dalam Dhewantara, 2010). Terdapat 2 macam CF yakni secara Footprint Primer dan Sekunder. Yang dimaksud dengan jejak karbon Primer adalah ukuran emisi $\mathrm{CO}_{2}$ yang bersifat langsung, dimana emisi ini didapat dari hasil pembakaran bahan bakar fosil seperti kendaraan dan transportasi lainnya, sedangkan jejak karbon sekunder adalah ukuran emisi $\mathrm{CO}_{2}$ yang bersifat tidak langsung, didapat dari daur ulang produk 
yang kita gunakan seperti dalam penggunaan listrik dan sebagainya (Walser, 2010, dalam Puri, 2009).

Menghitung jejak karbon akan menolong baik individu maupun kelompok untuk mengetahui seberapa besar sumbangan emisi karbon yang telah diberikan ke bumi pada suatu periode tertentu. Dengan kata lain, penghitungan jejak karbon untuk mengukur paparan karbon akibat gaya hidup dan konsumsi langsung individual atau kelompok terhadap barang dan jasa. Salah satu penghitungan jejak yang paling sederhana adalah konsumsi energi selama perjalanan dengan mobil.

Seperti sudah dipaparkan di atas, penyebab yang paling mungkin dari pemanasan global adalah besarnya jumlah emisi Gas Rumah Kaca (GRK)/Green House Gases selama aktifitas industri global. Gas rumah kaca terdiri atas karbon dioksida $\left(\mathrm{CO}_{2}\right)$, gas metan $(\mathrm{CH} 4)$, karbon monoksida $(\mathrm{CO})$, dinitrogen oksida (N2O), nitrogen oksida (NOx), dan sulfur dioksida (SO2), namun karbon dioksida adalah sumber utama emisi GRK pada saat ini (Sen, 2012). Emisi GRK yang dihasilkan akibat pemakaian bahan bakar fosil dari sektor transportasi sebesar $23 \%$ pada tahun 2007, dan diproyeksikan akan mencapai $29 \%$ pada 2030. Tingginya emisi GRK memicu terjadinya perubahan iklim, yang merupakan ancaman serius terhadap lingkungan sebagai bentuk konsekuensi dari pola-pola konsumsi dan gaya hidup yang tidak berkelanjutan (WCED, 1987 dalam Dhewantara, 2010). Batas aman konsentrasi $\mathrm{CO}_{2}$ di atmosfer adalah $350 \mathrm{ppm}$ sementara saat ini konsentrasinya telah mencapai level 390 ppm, dan terus meningkat sebesar 2 ppm per tahun (Jasmin, 2010).

Dalam kaitannya dengan pembangunan berkelanjutan (Sustainable Development), analisis jejak ekologi saat ini telah banyak digunakan sebagai indikator keberlanjutan suatu lingkungan. Baik jejak ekologi maupun jejak karbon dapat digunakan untuk mengukur besaran dampak yang dihasilkan dari aktivitas manusia dalam mengkonsumsi sumberdaya alam yang tersedia sehingga dapat dijadikan alat untuk perencanaan menuju pemanfaatan sumberdaya alam secara berkelanjutan (Rees dan Wackernagel, 1996).
Berdasarkan penelitian yang sudah dilakukan Dhewantara (2010), perhitungan jejak karbon atau emisi karbon dioksida yang dihasilkan dari sumber bergerak (mobile sources) dibedakan menjadi dua pendekatan, yaitu melalui pendekatan volume bahan bakar yang digunakan (fuel-used based) dan pendekatan jarak tempuh perjalanan (distance based). Perhitungan emsisi karbon dioksida dilakukan dengan cara mengalikan volume bahan bakar yang dikonsumsi dengan faktor emisi dari jenis bahan bakar yang dikonsumsi tersebut. Metode perhitungan berdasarkan fuel-used based memiliki tingkat reliabilitas yang lebih tinggi dibandingkan dengan metode distance based. Oleh karena itu disarankan menggunakan metode fuel used based dalam menghitung emisi $\mathrm{CO}_{2}$ dari konsumsi bahan bakar (World Resource Institute, 2007 dalam Dhewantara, 2010).

\section{Faktor Eksternalitas dan Internalitas \\ Saat ini di seluruh dunia terdapat} lebih dari 500 juta kendaraan bermotor. Jika setiap kendaraan membakar rata-rata hampir 2 galon bahan bakar per hari maka hal itu sama dengan mengkonsumsi sepertiga produksi minyak dunia. Apalagi dengan terus bertambahnya populasi manusia secara signifikan turut meningkatkan permintaan dan penggunaan kendaraan bermotor (Silver, 1999 dalam Dhewantara, 2010).

Konsumsi barang publik, seperti bahan bakar fosil, sering menimbulkan dampak eksternal atau disebut sebagai eksternalitas. Secara umum eksternalitas diartikan sebagai dampak baik positif maupun negatif dari tindakan satu pihak terhadap pihak lain (net cost atau benefit). Pada kenyataannya kedua dampak tersebut dapat muncul bersamaan dan terjadi secara simultan. Eksternalitas terjadi jika kegiatan produksi atau konsumsi dari satu pihak mempengaruhi kegunaan (utilitas) pihak lain (tidak diinginkan oleh pihak lain tersebut) dan pihak pembuat eksternalitas tidak menyediakan kompensasi terhadap pihak yang terkena dampak (Fauzi, 2006 dalam Septiarani, 2010). Secara singkat diartikan sebagai dampak yang dirasakan pihak ketiga yang disebabkan oleh suatu kegiatan transaksi atau kegiatan tertentu. Dampak tersebut terjadi dari empat interaksi pelaku ekonomi, yaitu antara produsen dan produsen, produsen dan konsumen, 
konsumen dan konsumen, serta konsumen dan produsen (Sutikno dan Maryunani, 2006 dalam Septiarani, 2010).

Koreksi terhadap eksternalitas dapat dilakukan melalui internalisasi (penyatuan proses pengambilan keputusan dalam satu unit usaha), pemberlakuan pajak (ketika pencemar harus membayar akibat kegiatannya yang mencemari lingkungan) dan dengan memfungsikan pasar. Untuk kasus eksternalitas negatif, berupa pencemaran, koreksi dapat dilakukan melalui pemberlakuan kebijakan antara lain berupa Sistem insentif-disinsentif (Fauzi, 2006 dalam Septiarani, 2010). Secara spesifik dihubungkan dengan emisi karbon, jika jejak karbon diketahui, maka strategi yang tepat untuk mengurangi emisi adalah melalui Carbon Diet atau cara-cara seperti Life Cycle Assessment (LCA), identifikasi konsumsi energi yang terkait dengan emisi $\mathrm{CO}_{2}$, optimalisasi energi untuk mengurangi emisi $\mathrm{CO}_{2}$ dan gas rumah kaca lainnya (Dhewantara, 2010).

Pada skala nasional, beberapa dokumen yang dikeluarkan oleh Indonesia sebagai pegangan departemen dan kementrian pun mulai disosialisasikan. Mulai dari identifikasi potensi penurunan emisi, sampai kepada rancangan kebijakan yang akan digunakan oleh Indonesia untuk menurunkan emisi dalam negeri. Salah satu dokumen yang dikeluarkan oleh Indonesia, Second National Communication, menyatakan bahwa emisi nasional Indonesia di tahun 2000 mencapai 556,499 Ggram $\mathrm{CO}_{2}-$ ekivalen. Emisi ini berasal dari seluruh sektor kecuali LULUCF (Land Use, Land Use
Change and Forestry) dan lahan gambut (IESR, 2011).

Selanjutnya disebutkan juga bahwa emisi $\mathrm{CO}_{2}$ dari konsumsi bahan bakar fosil dari tahun 2000-2005, naik hingga 6,4\% per tahunnya. Sumber bahan bakar utama dari kategori emisi ini berasal dari listrik, penyulingan minyak bumi dan gas $(35 \%)$; transportasi (23\%); permukiman $(9 \%)$ dan industri manufaktur serta konstruksi $(27 \%)$. Di tahun 2000, emisi gas rumah kaca melalui pembakaran bahan bakar fosil beranjak dari 240,877 Ggram di tahun 2000 sampai 333,438 Ggram di tahun 2005. Berdasarkan data yang diperoleh dari Second National Communication, dapat dikatakan bahwa emisi nasional Indonesia di tahun 2005 mencapai $1,13 \mathrm{~kg} \mathrm{CO}$-ek/kapita/hari (1130 g $\mathrm{CO}_{2}$-ek/kapita/hari) atau $411,33 \mathrm{~kg} \quad \mathrm{CO}_{2-}$ ek/kapita/tahun $\quad\left(0,411\right.$ ton $\mathrm{CO}_{2^{-}}$ ek/kapita/tahun) (IESR, 2011).

\section{Analisis Jejak Karbon (Studi Kasus Perbandingan di Kota Manado dan Kota Bandung)}

Berdasarkan data sekunder Sulawesi Utara dalam Angka tahun 2009, jumlah kendaraan bermotor di Sulawesi Utara adalah 217,754 unit yang terdiri dari berbagai jenis (Tabel 1). Sedangkan jumlah penduduk Sulawesi Utara adalah 2.121.017 jiwa pada tahun 2005. Selama tahun 2008 jasa pengangkutan menggulirkan dana sebesar Rp. 205,976 juta. Luas daratan $15,273 \mathrm{~km} 2$ (tahun 2008) dengan komposisi lahan sawah seluas 65,629 Hektar $(4,30 \%$ dari total) dan lahan kering sebesar 1,461,698 Ha $(95,70 \%$ dari total luas).

Tabel 1. Perbandingan Penduduk, Jumlah Kendaraan dan Luas Lahan Provinsi Jawa Barat dan Sulawesi Utara

\begin{tabular}{|l|l|l|l|l|}
\hline Keterangan & $\begin{array}{l}\text { Kepadatan } \\
\text { Penduduk } \\
\text { (jiwa/km2) }\end{array}$ & $\begin{array}{l}\text { Jumlah } \\
\text { penduduk }\end{array}$ & $\begin{array}{l}\text { Jumlah } \\
\text { Kendaraan }\end{array}$ & Luas Lahan \\
\hline $\begin{array}{l}\text { Jawa Barat (Dalam } \\
\text { Angka tahun 2009) }\end{array}$ & $1,441,24$ & $\begin{array}{l}42,19 \text { juta jiwa } \\
(2008), 39,96 \\
\text { juta jiwa } \\
(2005)\end{array}$ & $\begin{array}{l}6,835,197 \\
(2009), \\
6,144,750 \\
(2007)\end{array}$ & $\begin{array}{l}\text { luas lahan kering : 582,323 (24.79\%) } \\
\text { persen dari jumlah lahan kering) } \\
\text { Tegal/Kebun 576,565 Ha (24.55\%). } \\
\text { Luas sawah 378 856 Ha (40.09\%) dr } \\
\text { luas sawah lahan total }\end{array}$ \\
\hline $\begin{array}{l}\text { Bandung } \\
\begin{array}{l}\text { Sulawesi Utara } \\
\text { 2009) Angka }\end{array}\end{array}$ & 14234,53 & & & $\begin{array}{l}\text { lahan sawah seluas 65,629 Hektar } \\
(4,30 \% \text { dari total) dan lahan kering } \\
\text { sebesar 1,461,698 Ha }\end{array}$ \\
\hline Manado & $\begin{array}{l}\text { (2008) } \\
(2009)\end{array}$ & $\begin{array}{l}217,754 \\
(2009)\end{array}$ \\
\hline
\end{tabular}


Data di atas menunjukkan bahwa proporsi jumlah penduduk, jumlah kendaraan dan luas lahan di Sulawesi Utara cenderung lebih rendah dibandingkan dengan provinsiprovinsi di Pulau Jawa, khususnya kota-kota besar seperti Jakarta atau Bandung. Namun, bila dihubungkan dengan jumlah kendaraan serta luas areal produktif di Sulawesi Utara, angka tersebut masih relatif lebih rendah bila dibandingkan dengan angka yang sama di Kota Bandung (dibandingkan dengan penelitian Dhewantara, 2010), karena jumlah penduduk Kota Bandung yang lebih besar sementara luas areal produktif lebih kecil daripada Sulawesi Utara.

Pada pengukuran yang dilakukan Wackernagel et al., (2006), suplai lahan bioproduktif dan laut pada planet ini sebesar 1.8 hektar per orang. Jumlah tersebut akan berkurang jika terdapat spesies lain yang juga bergantung pada lahan itu. Namun jumlah tersebut jauh lebih kecil dibandingkan penduduk Kanada yang memerlukan rata-rata 7.5 hektar untuk memenuhi konsumsi perorang. Jika hal tersebut dibiarkan, itu artinya diperlukan 4 planet tambahan untuk memenuhi kebutuhan penduduk tersebut. Orang Italia menghasilkan jejak 4 gha, Meksiko 2,4 gha sedangkan orang India 0,7 gha.

Jika dibandingkan dengan persediaan dan permintaan, pada tahun 2002 sesungguhnya Ecological Footprint penduduk dunia telah melebihi kapasitas bumi lebih dari $20 \%$., dengan perhitungan 2.2 gha/orang/1.8gha/org=1.2, artinya diperlukan 1 tahun 2 bulan untuk meregenerasi sumber daya yang dikonsumsi manusia pada tahun tersebut. Fenomena itu disebut 'ecological overshoot'. Overshoot menyebabkan likuidasi dari sumberdaya alam seperti akumulasi karbon di atmosfer, kolapsnya perikanan, melebarnya areal deforestasi, kehilangan biodiversitas dan kekurangan air bersih. Oleh karena itu harus dilakukan efisiensi, yakni jejak ekologi manusia harus berkembang lebih lambat dibandingkan aktivitas ekonomi, meskipun pada kenyataannya permintaan manusia atas sumberdaya alam terus meningkat hingga pada tingkat dimana ekonomi manusia berada dalam 'overshoot' ekologi global (Wackernagel et al., 2006)

Beberapa aplikasi yang dapat dilakukan adalah dari Ecological Footprint antara lain menggunakan teknologi sumberdaya yang efisien untuk mengurangi permintaan terhadap sumberdaya alam; mengurangi konsumsi dengan meningkatkan kualitas hidup, misalnya membangun pedestrian untuk pejalan kaki yang lebih bersahabat untuk mengurangi kebutuhan akan bahan bakar fosil; mengurangi kepadatan penduduk melalui pembatasan jumlah anak; dan berinvestasi pada sumberdaya alam, dalam hal ini mengimplementasikan metode yang menghasilkan lebih terhadap produktivitas biologi lahan sehingga dapat meningkatkan suplai (Wackernagel et al., 2006).

Jejak ekologi penting diketahui dalam rangka mengantisipasi sistem transportasi. Soemarwoto (2006) telah memberikan telaahan yang dapat digunakan untuk mendorong masyarakat maupun pemerintah untuk merenungkan dan mengkaji ulang sistem transpor Indonesia serta dampaknya terhadap pembangunan berkelanjutan. Pertama, sistem transport yang berorientasi pada transport darat, mengingkari sifat Negara NKRI yang terdiri dari ribuan pulau, sehingga timbul persepsi bahwa laut adalah pemisah antara pulaupulau dan penduduk yang menghuninya. Dalam hal ini kebijakan transport orientasi darat tidak bersifat pro-NKRI. Dibutuhkan sebuah sistem transport antarmodalitas (intermodality) dalam sebuah jaring-jaring transport yang menjamin antar-konektivitas dan antar operasionalitas (interconnectivity and interoperability) yang berimbang dengan memberi tempat yang wajar pada transport antar pulau dengan kapal. Hal tersebut diharapkan menjadi sebuah sistem yang pro NKRI yang dapat memperkuat kesatuan NKRI. Selain itu, pulau-pulau luar sebagai penentu batas kedaulatan dan zone ekonomi eksklusif NKRI akan mendapat perhatian besar. Perkembangan ini juga dapat memacu pertumbuhan wisata bahari. Dengan demikian, sistem tersebut akan menyebarkan pembangunan dengan lebih merata ke seluruh nusantara, sehingga bersifat lebih adil.

Dengan berimbangnya sistem transport, terpadu antarmodalitas, antarkonektivitas dan antaroperasionalitas juga bersifat pro lingkungan hidup, karena lebih hemat energi dengan emisi gas buang yang lebih rendah pada berjalan kaki, bersepeda, kereta api dan kapal sebagai 
komponennya. Di daerah yeng berhutan, pembangunan kereta api mempunyai dampak lebih kecil daripada jalan raya dan jalan tol. Sifat pro lingkungan hidup juga ditunjang oleh berkurangnya kebutuhan lahan, khususnya lahan yang subur dengan prasarana irigasi yang bagus. Dengan pembangunan yang lebih merata di seluruh nusantara pembangunan industri dan pemukiman baru dapat ditata dengan rencanan tata ruang yang rasional (Soemarwoto, 2006).

Sistem transport juga akan bersifat pro rakyat miskin, ketika dampak sosial penggusuran petani dan buruh tani miskin dikurangi. Perpindahan ke lereng gunung atau ke kota yang mempunyai dampak lingkungan hidup biofisik, seperti banjir dan kekeringan serta dampak sosial yang berat dapat dikurangi. Lebih lanjut, pada saat mengalami kelangkaan Bahan Bakar Minyak, transport yang hemat energi menunjang pembangunan ekonomi. Subsidi BBM berkurang dan desakan menaikkan harga BBM dan energi ikutannya juga berkurang. Keresahan masyarakat, baik masyarakat umum, maupun masyarakat bisnis pun akan berkurang. Karena pembangunan yang merata, penciptaan lapangan pekerjaan pun dapat tercipta merata di seluruh nusantara. Lapangan pekerjaan itu mulai dari pekerja bangunan untuk pabrik dan perumahan, pembuat kapal di galangan kapal kecil dan besar serta awak kapal sampai pada insinyur dan tenaga kerja terdidik lainnya (Soemarwoto, 2006).

Meskipun demikian, terdapat pula kendala utama penerapan konsep ini, yakni munculnya persepsi bahwa pemilik modal akan rugi dan PAD (Pendapatan Asli Daerah) merosot. Lobi industri otomotif akan semakin kuat. Tetapi berdasarkan pengalaman yang terjadi selama ini, sistem transportasi yang sangat mengandalkan pada kendaraan bermotor tidak mungkin dapat berkelanjutan, karena makin parahnya kemacetan lalu lintas, pencemaran udara dan kebisingan, makin menyusutnya taman dan jalur hijau serta hilangnya lahan subur dengan prasarana irigasinya. Penerapan konsep ini dapat dilakukan secara bertahap misalanya dalam sebuah kota dengan menggunakan cara yang sesuai dengan karakterisitik kota tersebut, seperti busway di Jakarta.. Demikian juga dengan rencana monorail, MRT dan subway yang sedang direncakanan oleh Jakarta (Soemarwoto, 2006).

Hal lain yang perlu diupayakan adalah mengembangkan sumber energi baru yang ramah lingkungan seperti mengganti penggunaan bahan bakar fosil dengan produk bahan bakar nabati (BBN), serta mengembangkan teknologi angin dan sinar matahari sebagai sumber energi (Wackernagel, 2011).

\section{PENUTUP}

Analisis Ecological Footprint sangat bermanfaat sebagai indikator berkelanjutan. Dengan mengetahui total konsumsi yang dibutuhkan serta hasil buangan (emisi) yang dikeluarkan, dapat memberi pemahaman yang jelas, betapa biokapasitas bumi semakin tertekan. Kecepatan ektraksi manusia terhadap lingkungan jauh lebih tinggi dibandingkan kecepatan kemampuan daya dukung bumi menyerap / asimilasi. Oleh karena itu perlu adanya suatu perubahan pola hidup (lifestyle) maupun kebijakan yang lebih efisien terhadap lingkungan demi keberlanjutan hidup yang diharapkan.

\section{DAFTAR PUSTAKA}

Convention on Biological Diversity, 2010. Technical Series No. 53. Biodiversity Indicators and The 2010 Biodiversity Target. Sekretariat of the Convention on Biological Diversity.

Dhewantara, P.W. 2010. Analisis Jejak Karbon (Carbon Footprint) Penggunaan Kendaraan Bermotor oleh Siswa SMA (Studi Kasus SMAN 4 Bandung). Tesis. Universitas Padjadjaran, Bandung.

Institute for Essential Services Reform (IESR), 2011. Potensi Penurunan Emisi Indonesia Melalui Perubahan Gaya Hidup Individu. Kalkulator Jejak Karbon. http://www.iesr.or.id/files/report kjk.pdf

Jasmin, F. 2010. Ambang Batas CO2 di Atmosfer. http://iklimkarbon.com/2010/05/04/amb ang-batas-co2-di-atmosfer/ 
Jawa Barat Dalam Angka, tahun 2009 http://www.jabarprov.go.id/index.php/su $\underline{\mathrm{bMenu} / 804}$

Puri, R.A. 2009. Kajian Emisi $\mathrm{CO}_{2}$ Berdasarkan Tapak Karbon Sekunder dari Kegiatan Non Akademik di ITS Surabaya.

http://digilib.its.ac.id/public/ITS-

Undergraduate-16429-3307100055-

Paper.pdf

Sen, C. 2012. Algae Based Carbon Capture and Utilization feasibility study -initial analysis of carbon capture effect basen on Zhoushan case pre-study in China. Royal Institute of Technology.

Septiarani, A. 2010. Analisis Water Footprint Produksi Kain Serat Rami (Studi Kasus Koppontren Darussalam, Kecamatan Wanaraja, Kabupaten Garut). Tesis. Universitas Padjadjaran, Bandung.

Soemarwoto, O. 2006. Pembangunan Berkelanjutan: Antara Konsep dan Realitas. Ceramah Umum pada Ulang Tahun ke 80 Universitas Padjadjaran, Bandung.

Sulawesi Utara dalam Angka tahun 2009. Badan Pusat Statistik Provinsi Sulawesi Utara.

Wackernagel, M. 2011. Why Waiting for Climate Consensus Could Waste Your Future. Artikel GC GMEF, Nairobi.

Wackernagel, M. dan Rees, W. 1996. Our Ecological Footprint. Canada: New Society Publishers.

Wackernagel, M., J. Kitzes, D. Moran., S. Goldfinger and M. Thomas. 2006. The Ecological Footprint of Cities and Regions: Comparing Resource Availability with Resource Demand. Environment and Urbanization. International Intitute for Environment and Development (IIED) Vol. 18 (1): 103-112.

World Research Institute . Annual report 2005

http://pdf.wri.org/wri_annualreport_200 $\underline{5 . p d f}$
World Research Institute . Annual report $2006 . \quad$ http://pdf.wri.org/ wri_annualreport_2006.pdf 